Research Article

\title{
Finite Element Analysis of Residual Stress in the Diffusion Zone of Mg/Al Alloys
}

\author{
Yunlong Ding ${ }^{1}$ and Dongying Ju $\mathbb{D}^{1,2}$ \\ ${ }^{1}$ Department of Materials Science and Engineering, Saitama Institute of Technology, Fusaiji 1690, Fukaya, \\ Saitama 369-0293, Japan \\ ${ }^{2}$ Department of Materials Science and Engineering, University of Science and Technology Liaoning, Anshan 114051, China \\ Correspondence should be addressed to Dongying Ju; dyju@sit.ac.jp
}

Received 11 September 2017; Revised 9 November 2017; Accepted 25 December 2017; Published 27 March 2018

Academic Editor: Yuanshi Li

Copyright (c) 2018 Yunlong Ding and Dongying Ju. This is an open access article distributed under the Creative Commons Attribution License, which permits unrestricted use, distribution, and reproduction in any medium, provided the original work is properly cited.

\begin{abstract}
In this study, the finite element method was applied for analyzing the effect of annealing temperatures on residual stress in the diffusion zone of AZ31 Mg and $6061 \mathrm{Al}$ alloys. The microstructure and mechanical behavior of the diffusion zone were also investigated. Simulations on the annealing of the welded specimens at $200^{\circ} \mathrm{C}, 250^{\circ} \mathrm{C}$, and $300^{\circ} \mathrm{C}$ were conducted. Moreover, experiments such as diffusion bonding and annealing, analysis of residual stress by X-ray diffraction, elemental analysis using an electron probe microanalyzer, and microstructure investigation via scanning electron microscopy were performed for further investigation of the diffusion layers. According to the results of the simulations and experiments, the diffusion layers widen with increasing annealing temperatures, and the results of the simulations are in good agreement with those of the experiments. The microstructure and elemental distribution were the most uniform and the residual stress was the least for samples annealed at $250^{\circ} \mathrm{C}$. Thus, $250^{\circ} \mathrm{C}$ was found to be the most appropriate annealing temperature.
\end{abstract}

\section{Introduction}

The finite element method (FEM) has many applications in modern industry and technology because of the extensive use of computers [1-6]. This method is presently the most popular and fastest developing numerical method in aircraft, ballistic missile, automotive, shipbuilding, machine, and electrotechnics industries and is used in fields such as biomechanics, medicine, mechatronics, and materials technology. Computational methods mainly help optimize design processes [7-10].

In addition, FEM is used in plastic forming and can simulate the press forming of aluminum by selecting appropriate forming parameters for the material, such as pressure force and falling speed of the punch [11].

Recently, many investigations on the welding of $\mathrm{Mg} / \mathrm{Al}$ alloys have been conducted using FEM, especially on the analysis of residual stress during welding, because magnesium and aluminum alloys are widely used in aerospace, automotive, machine, electrical, and chemical industries owing to their superior properties [12-14]. Further, the combination of the superior properties of magnesium and aluminum alloys provides insight into the research of lightweight vehicles.

However, most studies have focused on the analysis of residual stress during butt welding, laser beam welding, or friction stir welding $[15,16]$. In contrast, this study considers a different welding process, diffusion bonding. To decrease the residual stress during diffusion bonding, annealing experiments, simulations, and investigations of residual stress by X-ray diffraction (XRD) were performed. To the best of our knowledge, this is the first study focusing on diffusion bonding between magnesium and aluminum alloys. Based on the results of this study, more extensive applications of FEM and diffusion bonding can be determined, and the properties of composite materials containing magnesium and aluminum alloys can be investigated. The composite materials can contribute to the realization of lightweight components. In addition, the depletion of resources and 
energy will decrease, thus mitigating environmental pollution.

\section{Materials and Methods}

In this study, AZ31 magnesium alloy and 6061 aluminum alloy were used for diffusion bonding and annealing. Simulations and experiments were performed to analyze residual stress and evaluate the microstructure.

2.1. Theoretical Analysis. During diffusion bonding and annealing, microstructures of the alloys vary with temperature, and at the same time, thermal stress is induced. If the stress exceeds the elastic limit, plastic deformation occurs. A series of varieties do not emerge individually but interact with each other. The theory for analyzing the interaction is called metallo-thermomechanics, which is the foundation of thermal treatment analysis.

When the AZ31 magnesium alloy and 6061 aluminum alloy are welded by diffusion bonding, diffusion between $\mathrm{Mg}$ and $\mathrm{Al}$ should be considered. The diffusion phenomenon can be analyzed by Fick's law and can be expressed by the following equation:

$$
\frac{\partial C}{\partial t}=D \frac{\partial^{2} C}{\partial x^{2}},
$$

where $C$ is the concentration of the element and $D$ is the diffusion coefficient representing the diffusion property of the material and is a function of $C$. In general, if the influence of the microstructure is ignored, the diffusion equation can be expressed based on element concentration as follows:

$$
\dot{C}=\operatorname{div}(D \operatorname{grad} C) \text {. }
$$

If the energy of the object is represented as $e=g+T \eta+\operatorname{tr}\left(\sigma \mathcal{E}^{e}\right)$, then the first law of thermodynamics can be written as follows:

$$
\dot{\rho} \dot{e}-\operatorname{tr}(\dot{\boldsymbol{\sigma} \dot{\varepsilon}})+\operatorname{div} \mathbf{h}=0 .
$$

If the Fourier law $(\mathbf{h}=k \operatorname{grad} T)$ is used, plastic work and latent heat of transformation are not considered, and terms related to elastic strain and hardening coefficient are ignored, then (3) can be written as follows:

$$
\rho c \dot{T}-k \operatorname{div}(\operatorname{grad} T)=0,
$$

where $\rho$ is the density of the material, $c$ is the specific heat, and $k$ is the thermal conductivity. When the coefficient of heat transfer and the temperature of the fluid in contact with the object do not change, the boundary condition is expressed by the following equation:

$$
-k \operatorname{grad} T \cdot \mathbf{n}=h(T)\left(T-T_{\omega}\right),
$$

where $\mathbf{n}$ is a vector whose direction is outward from the surface of the object, $T_{\omega}$ is the temperature of the object's environment, and $h(T)$ is the coefficient of heat transfer between the object and the environment. Generally, the coefficient of heat transfer is a function of temperature $T$ and

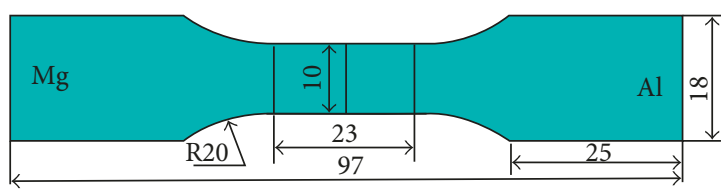

Figure 1: Analysis model.

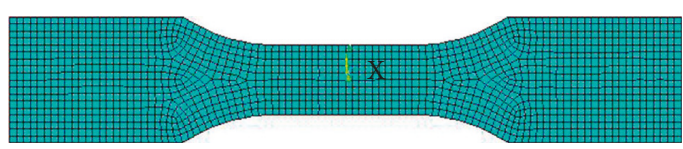

Figure 2: Finite element mesh.

can be obtained from the experimental value of the cooling curve [17].

When plastic materials are subjected to loading, they undergo elastic or plastic deformation. Hooke's law is applicable to three-dimensional stress and strain and can be expressed as

$$
\dot{\varepsilon}_{i j}=\dot{\varepsilon}_{i j}^{\mathrm{e}}+\dot{\varepsilon}_{i j}^{\mathrm{p}}+\dot{\varepsilon}_{i j}^{\mathrm{T}},
$$

where $\dot{\varepsilon}_{i j}$ is the total strain rate, $\dot{\varepsilon}_{i j}^{e}$ is the elastic strain rate, $\dot{\varepsilon}_{i j}^{\mathrm{p}}$ is the plastic strain rate, and $\varepsilon_{i j}^{\mathrm{T}}$ is the thermal strain rate. Elastic strain rate and thermal strain rate are expressed by the following equation:

$$
\begin{aligned}
& \dot{\varepsilon}_{i j}^{\mathrm{e}}+\dot{\varepsilon}_{i j}^{\mathrm{T}}=E_{i j k l}^{\mathrm{e}} \dot{\sigma}_{k l}+\beta_{i j} \dot{T}, \\
& \beta_{i j}=\frac{\partial E_{i j k l}^{\mathrm{e}}}{\partial T} \sigma_{k l}+\alpha_{i j} \frac{\partial \alpha_{i j}}{\partial T}\left(T-T_{0}\right),
\end{aligned}
$$

where $\alpha$ is the linear coefficient of expansion and $T-T_{0}$ is the temperature difference. $E_{i j k l}^{\mathrm{e}}$ is a coefficient that is represented by the following equation:

$$
E_{i j k l}^{\mathrm{e}}=\frac{1}{2 G}\left\{\left(\delta_{i k} \delta_{j l}+\delta_{i l} \delta_{j k}\right)-\frac{\nu}{1+\nu} \delta_{i j} \delta_{k l}\right\},
$$

where $v$ and $G$ are Poisson's ratio and the shear modulus, respectively. The plastic strain rate is expressed as follows:

$$
\begin{aligned}
\dot{\varepsilon}_{i j}^{p} & =\frac{1}{\hat{G}}\left(\frac{\partial F}{\partial \sigma_{m n}} \sigma_{m n}+\frac{\partial F}{\partial T} \dot{T}\right) \frac{\partial F}{\partial \sigma_{i j}}, \\
\frac{1}{\hat{G}} & =-\frac{1}{(\partial F / \partial \kappa)\left(\partial F / \partial \sigma_{k l}\right) \sigma_{k l}}, \quad F=F(\sigma, T),
\end{aligned}
$$

where $F$ is the Mises yield function.

First, the definition of the mixture and the mixing rule are explained. Intermetallic compounds, such as $\mathrm{Al}_{3} \mathrm{Mg}_{2}$ and $\mathrm{Mg}_{17} \mathrm{Al}_{12}$, are formed during diffusion bonding between magnesium and aluminum alloys. It is assumed that many microstructures are present in the mixture. Further, the mixture contains $N$ compositions whose volume fractions are $\xi_{I}(I=1,2, \ldots, N)$; the sum of the volume fractions of the compositions is 1 : 


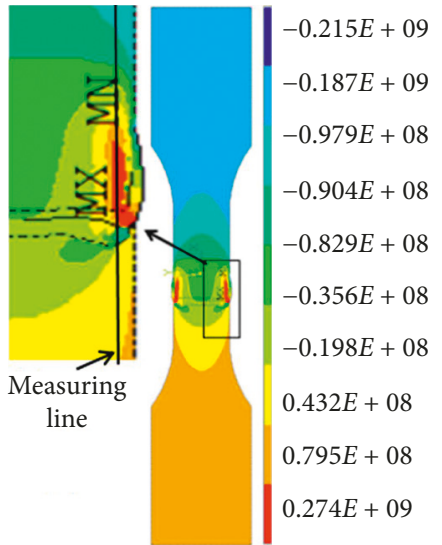

(a)

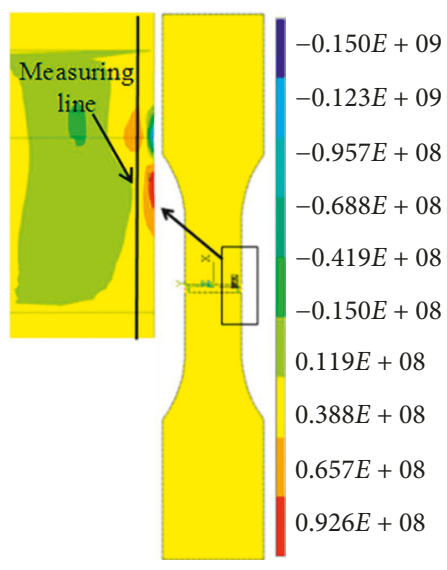

(c)

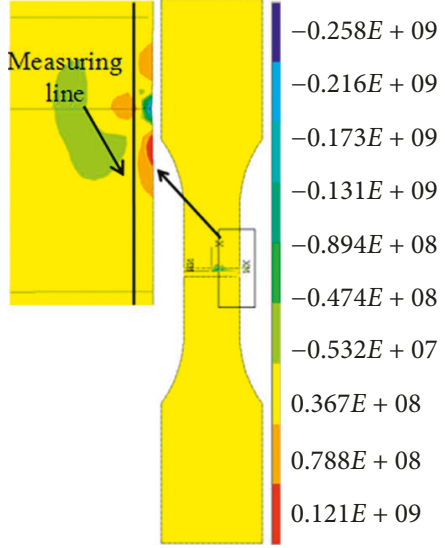

(b)

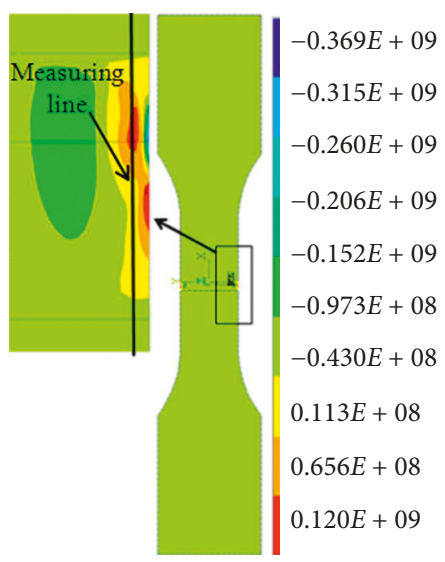

(d)

Figure 3: Results of simulations: (a) without annealing and annealing at $200^{\circ} \mathrm{C}$ (b), $250^{\circ} \mathrm{C}$ (c), and $300^{\circ} \mathrm{C}$ (d), previously presented in [20].

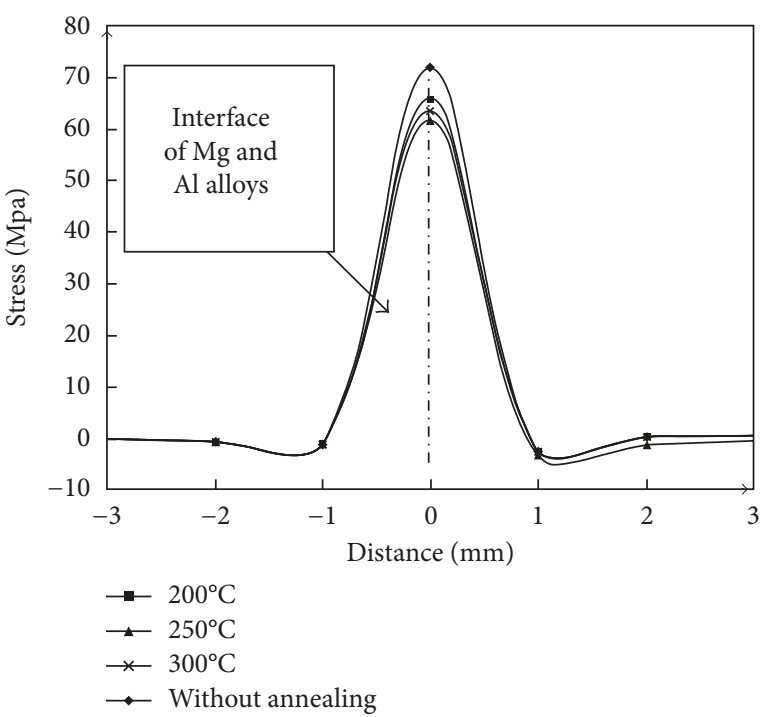

FIGURE 4: Distribution of residual stress obtained by simulation, previously presented in [20].

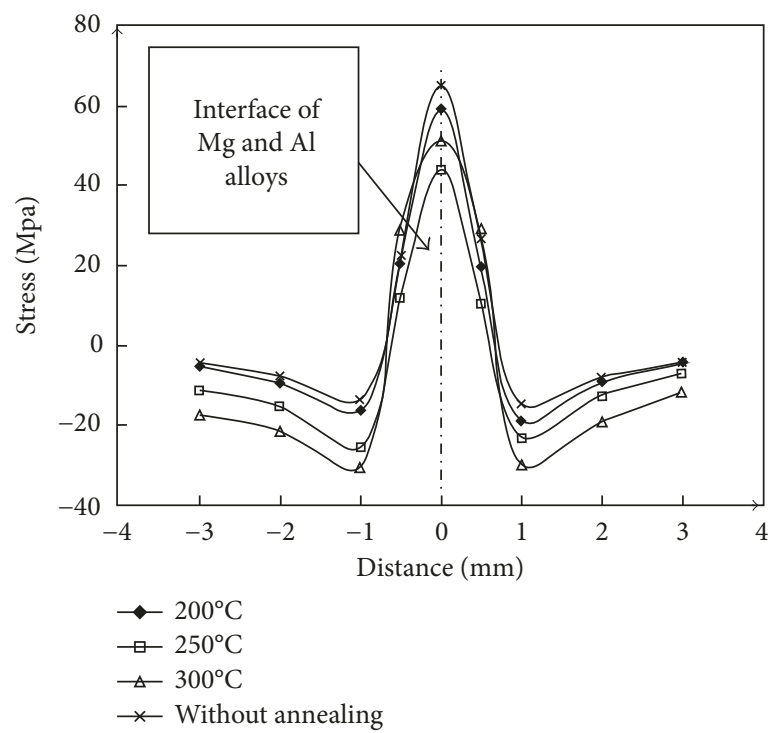

FIgURE 5: Residual stress of specimens annealed at different temperatures. 

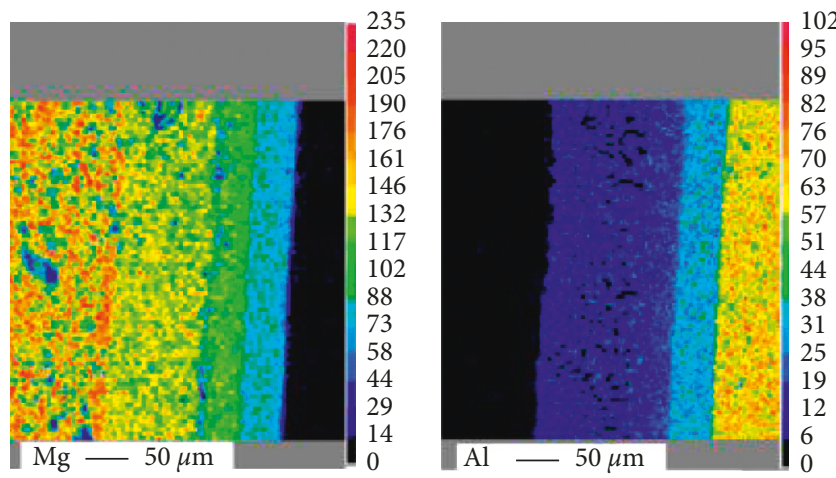

(a)
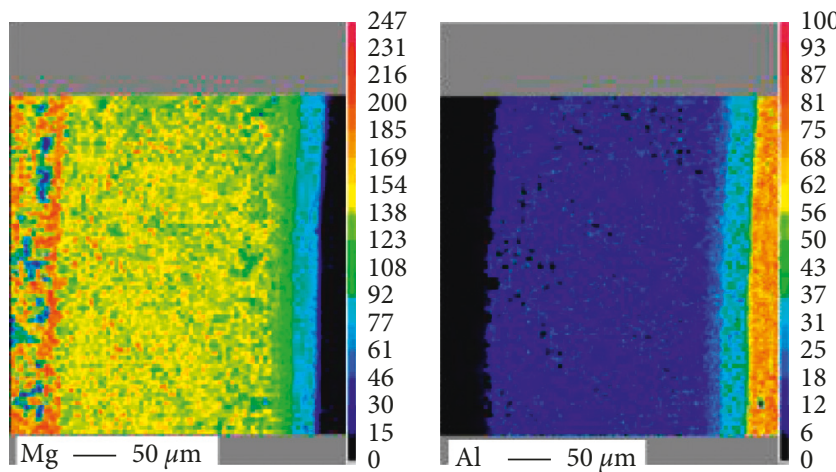

(c)
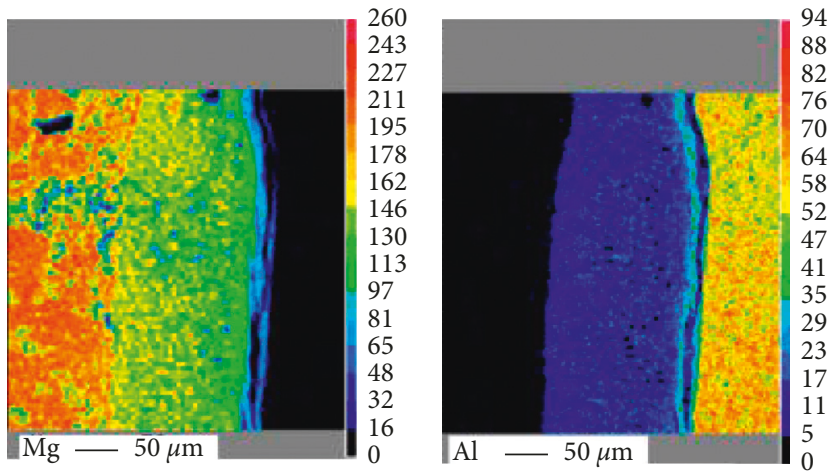

(b)
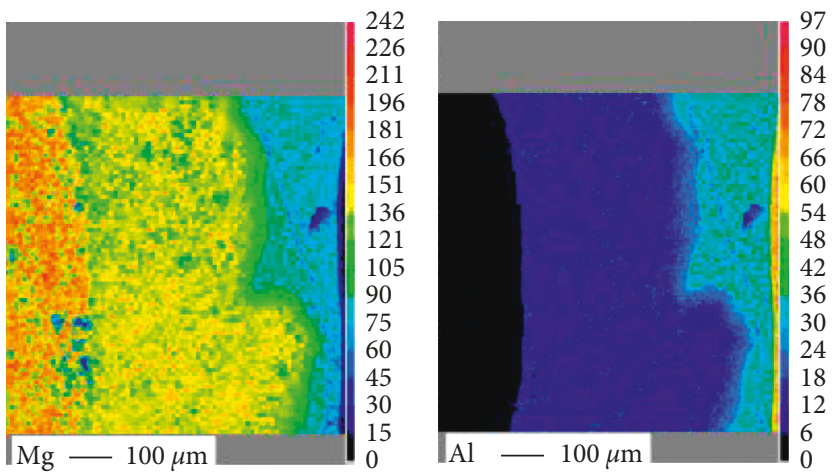

(d)

Figure 6: Results of elemental analysis, surface scanning: (a) without annealing and annealing at (b) $200^{\circ} \mathrm{C}$, (c) $250^{\circ} \mathrm{C}$, and (d) $300^{\circ} \mathrm{C}$.

$$
\sum_{I=1}^{N} \xi_{I}=1
$$

If the properties of composition $I$ are represented by $\chi_{I}$, then $\chi$ denotes all the properties of $N$ compositions. Therefore, the property $\chi$ can be expressed as (11), which is called the mixing rule [18]:

$$
\chi=\sum_{I=1}^{N} \chi_{I} \xi_{I}, \quad \xi_{I}(I=1,2, \ldots, N) \text {. }
$$

In the intermetallic compounds of $\mathrm{Mg}$ and $\mathrm{Al}$ alloys, the ratio of atomic quantity can be expressed as the following equation:

$$
\frac{M_{1}}{M_{2}}=\frac{C_{1} \cdot \mathrm{Ar}_{2}}{C_{2} \cdot \mathrm{Ar}_{1}}
$$

where $M_{1}$ and $M_{2}$ are the quantity of $\mathrm{Mg}$ and $\mathrm{Al}$ atoms. $C_{1}$ and $C_{2}$ are the atomic mass of $\mathrm{Mg}$ and $\mathrm{Al}$. $\mathrm{Ar}_{1}$ and $\mathrm{Ar}_{2}$ are the relative molecular masses.

The molar concentration of $\mathrm{Mg}$ is expressed as follows:

$$
C_{B 1}=\frac{M_{1}}{V_{0} \cdot N_{\mathrm{A}}},
$$

where $V_{0}$ is the volume of the intermetallic compounds and $N_{\mathrm{A}}$ is the Avogadro constant. The amount of substance for $\mathrm{Mg}$ is represented as follows:

$$
n_{1}=\frac{G_{1}}{\mathrm{Ar}_{1} \cdot g}
$$

where $G_{1}$ is the weight of $\mathrm{Mg}$ and $g$ is the gravitational acceleration.

So the volume ratio of $\mathrm{Mg}$ to $\mathrm{Al}$ can be expressed as follows:

$$
\frac{V_{1}}{V_{2}}=\frac{G_{1} \cdot C_{2}}{G_{2} \cdot C_{1}},
$$

$V_{1}$ and $V_{2}$ are the volume of $\mathrm{Mg}$ and $\mathrm{Al}$ and $G_{2}$ is the weight of $\mathrm{Al}$.

According to the mixing rule and the volume ratio of $\mathrm{Mg}$ to $\mathrm{Al}$, the coefficients of simulations can be calculated. Thermal-stress coupling field of ANSYS was applied to simulate stress at different temperatures during the diffusion process and annealing process. The element type was "Coupled Field, Vector Quad 13," and the material model was "Structural" and "Thermal." Temperature conditions were $200^{\circ} \mathrm{C}, 250^{\circ} \mathrm{C}, 300^{\circ} \mathrm{C}$, and room temperature $\left(20^{\circ} \mathrm{C}\right)$. It was assumed that the interface could not move during the diffusion process. Therefore, a fixed boundary condition was applied to the contact surface, and then the simulations were performed. The model is shown in Figure 1.

The finite element mesh is shown in Figure 2. The element size was $1 \mathrm{~mm}$, and the total number of elements was 14,005 . 


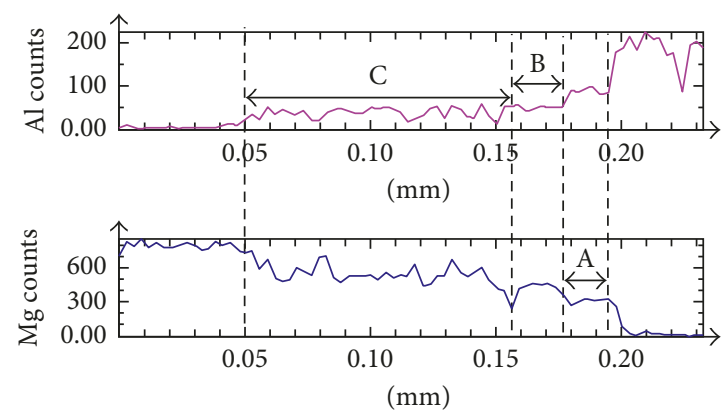

(a)

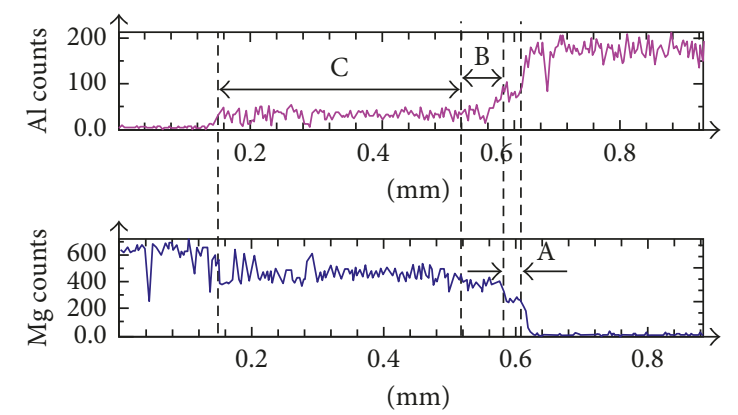

(c)

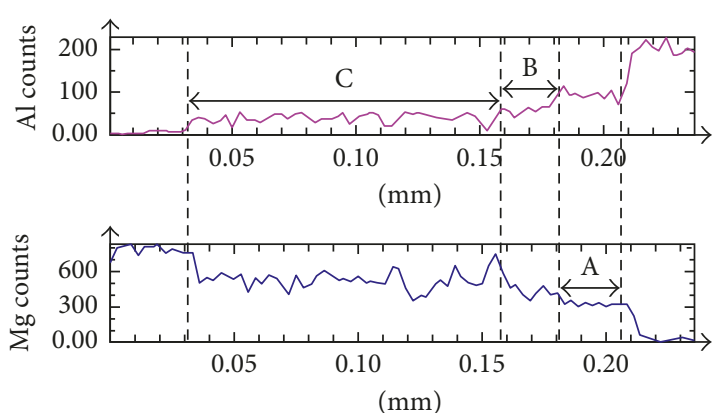

(b)

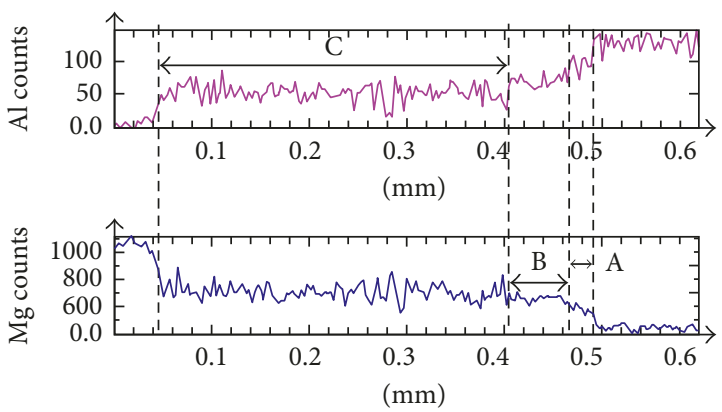

(d)

Figure 7: Results of elemental analysis, line scanning: (a) without annealing and annealing at (b) $200^{\circ} \mathrm{C}$, (c) $250^{\circ} \mathrm{C}$, and (d) $300^{\circ} \mathrm{C}$.

2.2. Experimental. The AZ31 magnesium alloy sheets and 6061 aluminum alloy sheets were successfully welded using vacuum diffusion bonding. The joining temperature was $440^{\circ} \mathrm{C}$. After vacuum diffusion bonding, the samples were annealed at 200,250 , and $300^{\circ} \mathrm{C}$. After heat treatment, the samples were cooled to room temperature in an electric furnace.

$\mathrm{XRD}$ was used to investigate the residual stress distribution of the specimens annealed at different temperatures. Based on the testing principle of residual stress, the $\mathrm{X}$-ray was adjusted. Initially, the specimen was radiated, and the corresponding diffraction angle $2 \theta$ was obtained, which was later used to calculate the slope $M$ of $2 \theta-\sin ^{2} \psi$ ( $\psi$ was set as $0^{\circ}, 15^{\circ}, 30^{\circ}$, and $45^{\circ}$ ). In addition, the relationship between $2 \theta$ and $\sin ^{2} \psi$ was obtained, and the residual stress $\sigma$ was calculated according to the following equation:

$$
\sigma=\frac{K \cdot \Delta 2 \theta}{\Delta \sin ^{2} \psi}=K \cdot M,
$$

where $K$ is the stress constant of the XRD analysis and can be expressed as follows:

$$
K=-\frac{1}{2} \cdot \cot \theta_{0} \cdot \frac{E}{1+v} \cdot \frac{\pi}{180},
$$

where $E$ is the elastic modulus of the material, $\theta_{0}$ is the diffraction angle without stress, and $v$ is Poisson's ratio [19].

For the $6061 \mathrm{Al}$ alloy, $2 \theta$ was set as $140^{\circ}$, the stress constant was $-163.32 \mathrm{MPa} /{ }^{\circ}$, tube type was $\mathrm{Cr}$, wavelength was $\mathrm{k} \alpha$, and the size of the collimator was $\varphi=0.5 \mathrm{~mm}$. For the AZ31 Mg alloy, $2 \theta$ was set as $155^{\circ}$ and stress constant was $-79.14 \mathrm{MPa} /{ }^{\circ}$; tube type, wavelength, and the size of the collimator were the same as that for the $6061 \mathrm{Al}$ alloy. In addition, the $2 \theta$ of $\mathrm{Mg}_{17} \mathrm{Al}_{12}$ and $\mathrm{Al}_{3} \mathrm{Mg}_{2}$ were set as $150^{\circ}$ and $145^{\circ}$ and their stress constants were $-98.97 \mathrm{MPa} /{ }^{\circ}$ and $-126.22 \mathrm{MPa} /{ }^{\circ}$, respectively. Based on these values, the values of residual stress were calculated.

Furthermore, the microstructure and elemental distribution of the diffusion zone were investigated by SEM and EPMA.

\section{Results and Discussion}

The Mises stress data were obtained after completion of the simulation. The simulation results of stress distribution are shown in Figures 3(a)-3(d).

Figure 3 shows that the stress values change with annealing temperature. Because stress is mainly concentrated at the edge of the interface, the values along the interface are the largest, which in turn causes premature failure [20].

In this paper, stress distribution along the line crossing the edge of the interface was investigated (the measuring line is shown in Figure 3). Based on the stress values at the nodes and the distance between the nodes, Figure 4 is obtained; this figure shows the distribution of residual stresses calculated from the simulations.

Residual stress is a vector, and in this study, its direction was along the axial direction of the specimens. According to material mechanics, tensile stress is positive, while compressive stress is negative. Therefore, it could be concluded from Figure 4 that the value of stress near the interface was positive, that is, tensile stress, and the largest. The stress near the interface of the specimens annealed at temperatures of 


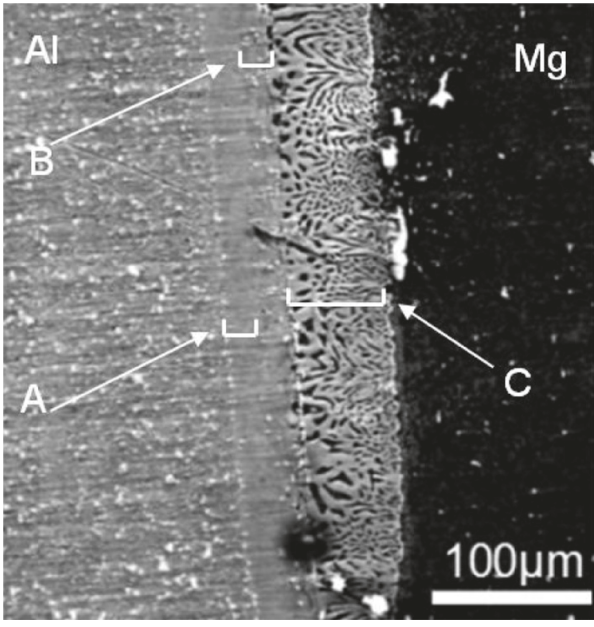

(a)

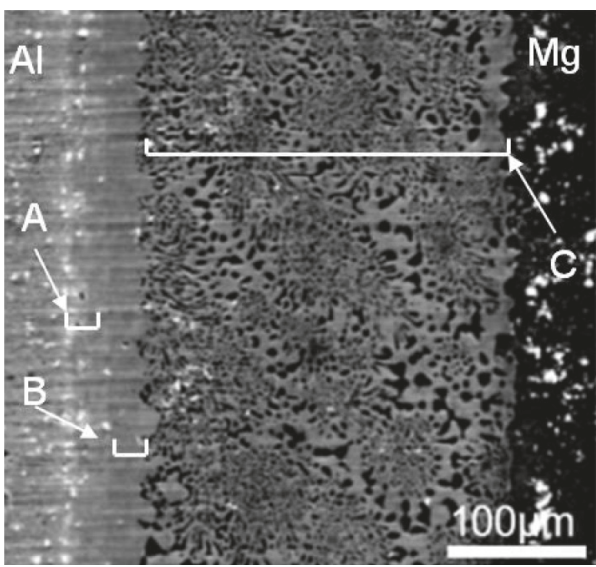

(c)

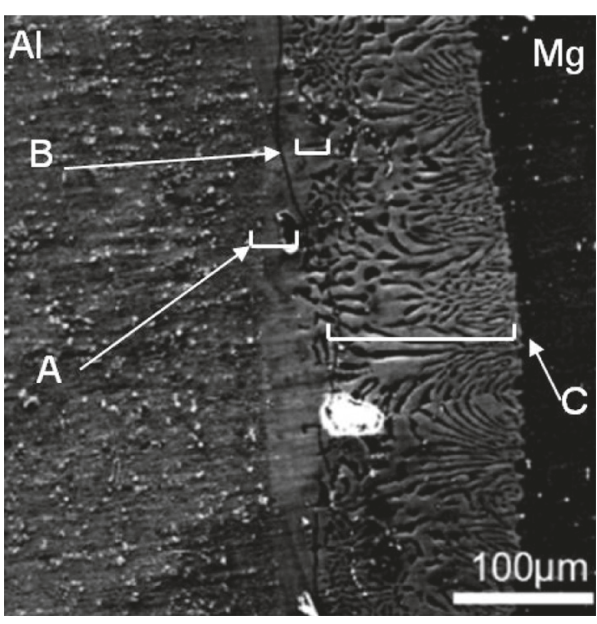

(b)

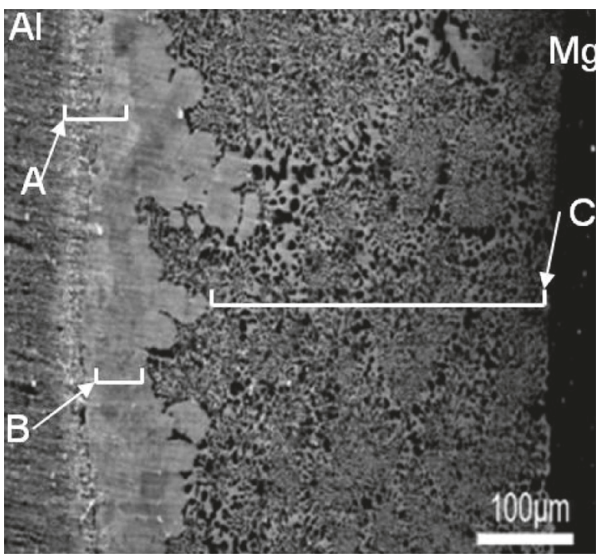

(d)

Figure 8: SEM micrographs of joints: (a) without annealing and annealing at (b) $200^{\circ} \mathrm{C}$, (c) $250^{\circ} \mathrm{C}$, and (d) $300^{\circ} \mathrm{C}$; layer $\mathrm{A}$ : $\mathrm{Al}_{3} \mathrm{Mg}_{2}$, layer B: $\mathrm{Mg}_{17} \mathrm{Al}_{12}$, and layer C: Mg-based solid solution.

200,250 , and $300^{\circ} \mathrm{C}$ was 66,61 , and $63 \mathrm{MPa}$, respectively. The untreated specimens exhibited a stress value of $71 \mathrm{MPa}$. However, as the distance from the interface increased, stress decreased and even became negative, that is, compressive stress. In addition, the residual stress was almost $0 \mathrm{MPa}$ far away from the interface.

The residual stress measured by XRD is shown in Figure 5.

The stress of the untreated specimens was about $65 \mathrm{MPa}$, while that of the specimens annealed at $300^{\circ} \mathrm{C}$ and $200^{\circ} \mathrm{C}$ was $51 \mathrm{MPa}$ and $59 \mathrm{MPa}$, respectively. However, when the specimens were annealed at $250^{\circ} \mathrm{C}$, the stress was approximately $44 \mathrm{MPa}$. During the experiments, the diffraction peak for the (311) plane of $\mathrm{Al}$ appeared at a $2 \theta$ of about $139^{\circ}$, while that for the (104) plane of $\mathrm{Mg}$ appeared at a $2 \theta$ of $152^{\circ}$. Furthermore, the $2 \theta$ value of the intermetallic compounds near $\mathrm{Al}$ and $\mathrm{Mg}$ was $139.4^{\circ}$ and $143^{\circ}$, respectively [21]. Thus, it could be concluded that the distribution of residual stress obtained from the experiments is nearly the same as that obtained from simulations.

The above results showed that $250^{\circ} \mathrm{C}$ is the most appropriate annealing temperature. This could be further confirmed by microstructure investigation. The results of the elemental analysis are shown in Figures 6 and 7. In Figure 6, the colors represent the different amounts of elements detected, and the $y$-axis numbers represent the levels that the different colors stand for.

As shown in Figures 6 and 7, the diffusion layers widened with increasing annealing temperatures. As the temperature increased, the magnesium and aluminum contents varied in regions $\mathrm{A}, \mathrm{B}$, and $\mathrm{C}$. Specifically, the untreated specimens exhibited a magnesium content ranging from 800 to 300 counts, while the aluminum content was 50-200 counts. For the specimens annealed at $200^{\circ} \mathrm{C}$, the $\mathrm{Mg}$ content ranged from 600 to 300 counts in the direction from $\mathrm{Mg}$ to $\mathrm{Al}$, while the $\mathrm{Al}$ content was $50-100$ counts in the same direction. However, for the specimens annealed at $300^{\circ} \mathrm{C}$, the $\mathrm{Mg}$ content varied from 800 to 650 counts, while the $\mathrm{Al}$ content varied within the range of 50-70 counts. The result for the specimens annealed at $250^{\circ} \mathrm{C}$ is shown in Figure $7(\mathrm{c})$. For this specimen, the magnesium content ranged from 500 to 300 counts, while the Al content was 50-70 counts. The reason for the variations in the diffusion layer width and element content was the difference in the annealing temperature. As the annealing temperature increased, the diffusion rate 


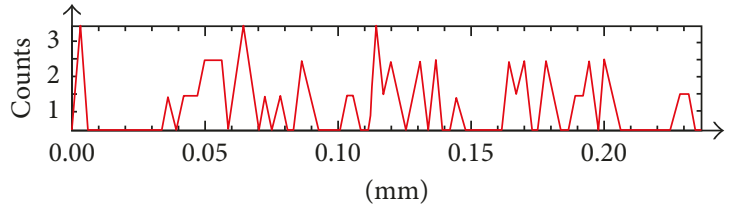

(a)

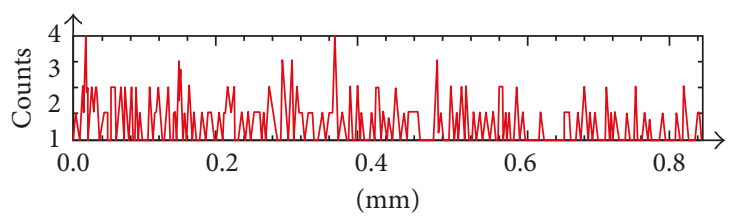

(c)

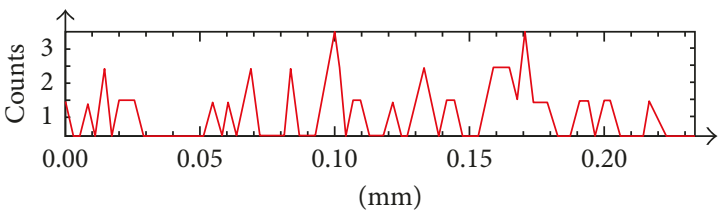

(b)

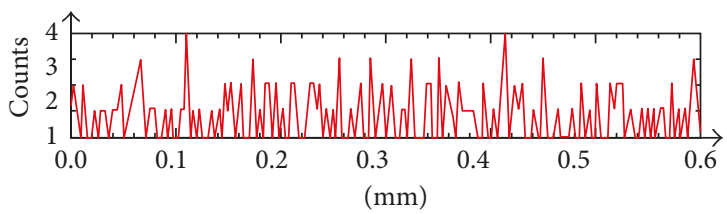

(d)

Figure 9: Elemental distribution of $\mathrm{Zn}$, line scanning: (a) without annealing and annealing at (b) $200^{\circ} \mathrm{C}$, (c) $250^{\circ} \mathrm{C}$, and (d) $300^{\circ} \mathrm{C}$.

increased. Therefore, the diffusion layers were the widest for the specimens annealed at $300^{\circ} \mathrm{C}$. However, as shown in Figure 7, the element content for the specimens annealed at $250^{\circ} \mathrm{C}$ was steady. This indicates that the microstructure is more uniform at $250^{\circ} \mathrm{C}$.

To verify the above results, the microstructures of the specimens annealed at different temperatures were investigated. The microstructures of the joints are shown in Figure 8.

The diffusion layers, including layers $\mathrm{A}, \mathrm{B}$, and $\mathrm{C}$, which were investigated and confirmed to be $\mathrm{Al}_{3} \mathrm{Mg}_{2}, \mathrm{Mg}_{17} \mathrm{Al}_{12}$, and $\mathrm{Mg}$-based solid solutions, respectively, could be clearly observed. Moreover, the width of the diffusion layers increased with increasing annealing temperature. However, the microstructure of the specimens annealed at $250^{\circ} \mathrm{C}$ was more uniform than that of those annealed at other conditions, thus confirming the results of the elemental distribution analysis.

As shown in Figure 9, for specimens annealed at $250^{\circ} \mathrm{C}$, the $\mathrm{Zn}$ content was relatively steady and was greater than that for specimens annealed at other temperatures. Although $\mathrm{Zn}$ is a kind of rare earth element and its content is low, it greatly affects the diffusion zone of $\mathrm{Mg}$ and $\mathrm{Al}$ alloys. $\mathrm{Zn}$ could retard the formation of intermetallic compounds of $\mathrm{Mg}$ and Al. Though intermetallic compounds were formed, they precipitated and were dispersed, thus generating precipitation strength [22]. In other words, the amount of the hard and brittle phase at the interface was small. Thus, the properties of the specimens annealed at $250^{\circ} \mathrm{C}$ were better than those of the specimens annealed at other temperatures.

\section{Conclusions}

The following results were obtained from the simulations and experiments:

(1) Annealing temperatures have a great effect on the microstructure and elemental distribution. The most appropriate annealing temperature for the diffusionbonded $\mathrm{Mg} / \mathrm{Al}$ alloy is $250^{\circ} \mathrm{C}$.

(2) It is difficult to obtain a sufficiently high-quality diffusion zone by diffusion bonding magnesium and aluminum alloy sheets because of the formation of intermetallic compound layers. However, this study used annealing to improve the microstructure, thus achieving such a diffusion zone.

(3) The outcomes obtained by FEM are in good agreement with those of the experiments; thus, the accuracy of FEM for analyzing residual stress during annealing is reliable.

\section{Conflicts of Interest}

The authors declare that they have no conflicts of interest.

\section{Acknowledgments}

This research work has been partially supported by the grant subsidy of the "Nano Project" for Private Universities: 2011-2014 from MEXT, Japan. This study was also supported by the "Advanced Science Research Laboratory" in Saitama Institute of Technology.

\section{References}

[1] W. Walke, Z. Paszenda, and W. Jurkiewicz, "Numerical analysis of three-layer vessel stent made from $\mathrm{Cr}-\mathrm{Ni}$-Mo steel and tantalum international," Journal of Computational Materials Science and Surface Engineering, vol. 1, no. 1, pp. 129-139, 2007.

[2] T. Da Silva Botelho, E. Bayraktar, and G. Inglebert, "Experimental and finite element analysis of spring back in sheet metal forming," International Journal of Computational Materials Science and Surface Engineering, vol. 1, no. 2, pp. 197-213, 2007.

[3] A. V. Benin, A. S. Semenov, and S. G. Semenov, "Modelling of fracture process in concrete reinforced structures under steel corrosion," Journal of Achievements in Materials and Manufacturing Engineering, vol. 39, no. 2, pp. 168-175, 2010.

[4] S. Thipprakmas, M. Jin, K. Tomokazu, Y. Katsuhiro, and M. Murakawa, "Prediction of Fineblanked surface characteristics using the finite element method (FEM)," Journal of Materials Processing Technology, vol. 198, no. 1, pp. 391-398, 2008. 
[5] Y. Kim, S. Yaang, D. Shan, S. Choi, S. Lee, and B. You, "Threedimensional rigid-plastic FEM simulation of metal forming processes," Journal of Materials Engineering and Performance, vol. 15 , no. 3, pp. 275-279, 2006.

[6] K. Lenik and D. Wójcicka-Migasiuk, "FEM applications to the analysis of passive solar wall elements," Journal of Achievements in Materials and Manufacturing Engineering, vol. 43, no. 1, pp. 333-340, 2010.

[7] J. Okrajni and W. Essler, "Computer models of steam pipeline components in the evaluation of their local strength," Journal of Achievements in Materials and Manufacturing Engineering, vol. 39, no. 1, pp. 71-78, 2010.

[8] J. Bouzakis, G. Maliaris, and A. Tsouknidas, "FEM supported semi-solid high pressure die casting process optimization based on rheological properties by isothermal compression tests at thixo temperatures extracted," Computational Materials Science, vol. 59, pp. 133-139, 2012.

[9] B. Regener, C. Krempaszky, E. Werner, and M. Stockinger, "Modelling the micromorphology of heat treated Ti6Al4V forgings by means of spatial tessellations feasible for FEM analyses of microscale residual stresses," Computational Materials Science, vol. 52, no. 1, pp. 77-81, 2012.

[10] Z. Shiping, O. El Kerdi, K. A. Khurram, and G. Habashi, "FEM analysis of in-flight ice break-up," Finite Elements in Analysis and Design, vol. 57, pp. 55-66, 2012.

[11] U. E. Ozturk and G. Anlas, "Finite element analysis of expanded polystyrene foam under multiple compressive loading and unloading," Materials and Design, vol. 32, no. 2, pp. 773-780, 2011.

[12] J. Shang, K.-H. Wang, Q. Zhou, D.-K. Zhang, J. Huang, and J. Q. Ge, "Effect of joining temperature on microstructure and properties of diffusion bonded $\mathrm{Mg} / \mathrm{Al}$ joints," Transactions of Nonferrous Metals Society of China, vol. 22, no. 8, pp. 1961-1966, 2012.

[13] X. Li, W. Liang, X. Zhao, Y. Zhang, X. Fu, and F. Liu, "Bonding of $\mathrm{Mg}$ and $\mathrm{Al}$ with $\mathrm{Mg}-\mathrm{Al}$ eutectic alloy and its application in aluminum coating on magnesium," Journal of Alloys and Compounds, vol. 471, no. 1-2, pp. 408-411, 2009.

[14] F. Liu, D. Ren, and L. Liu, "Effect of Al foils interlayer on microstructures and mechanical properties of $\mathrm{Mg}$-Al butt joints welded by gas tungsten arc welding filling with $\mathrm{Zn}$ filler metal," Materials and Design, vol. 46, pp. 419-425, 2013.

[15] J. R. Cho, B. Y. Lee, Y. H. Moon, and C. J. Van Tyne, "Investigation of residual stress and post weld heat treatment of multi-pass welds by finite element method and experiments," Journal of Materials Processing Technology, vol. 155-156, pp. 1690-1695, 2004.

[16] P.-H. Chang and T.-L. Teng, "Numerical and experimental investigations on the residual stresses of the butt-welded joints," Computational Materials Science, vol. 29, no. 4, pp. 511-522, 2004.

[17] D. Y. Ju, "Actuality and scope on simulation of heat treatment III: simulation of carburized and nitrided quenching process," Journal of the Society of Materials Science, vol. 55, no. 7, pp. 712-717, 2006.

[18] T. Inoue, "Inelastic constitutive models under plasticity-creep interaction condition - theories and evaluations," JSME International Journal. Series 1, Solid Mechanics, Strength of Materials, vol. 31, no. 4, pp. 653-663, 1988.

[19] J. G. Wang and D. Y. Ju, Study on Evolution Technology of Anisotropic Mechanical Properties and Microstructure Evolution of Metal Thin Plate under Complex Stress Condition, Saitama Institute of Technology, Saitama, Japan, 2011.
[20] Y. L. Ding, J. Wang, and D. Ju, "Simulations about the effect of heat treatment temperatures on the properties of diffusion bonded $\mathrm{Mg} / \mathrm{Al}$ joints," MATEC Web of Conferences, vol. 130, p. 06004, 2017.

[21] D. Zhang and J. He, Residual Stress Analysis by X-Ray Diffraction and it's Functions, Xi'an Jiaotong University, Xi'an, China, 1st edition, 1999.

[22] L. M. Zhao and Z. D. Zhang, "Effect of Zn alloy interlayer on interface micro-structures and strength of diffusion-bonded Mg-Al joints," Scripta Materialia, vol. 58, no. 4, pp. 283-286, 2008. 


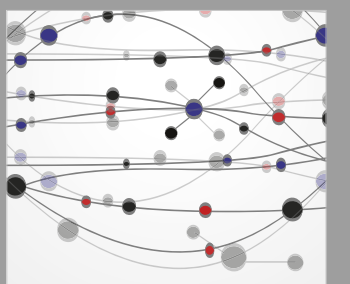

The Scientific World Journal
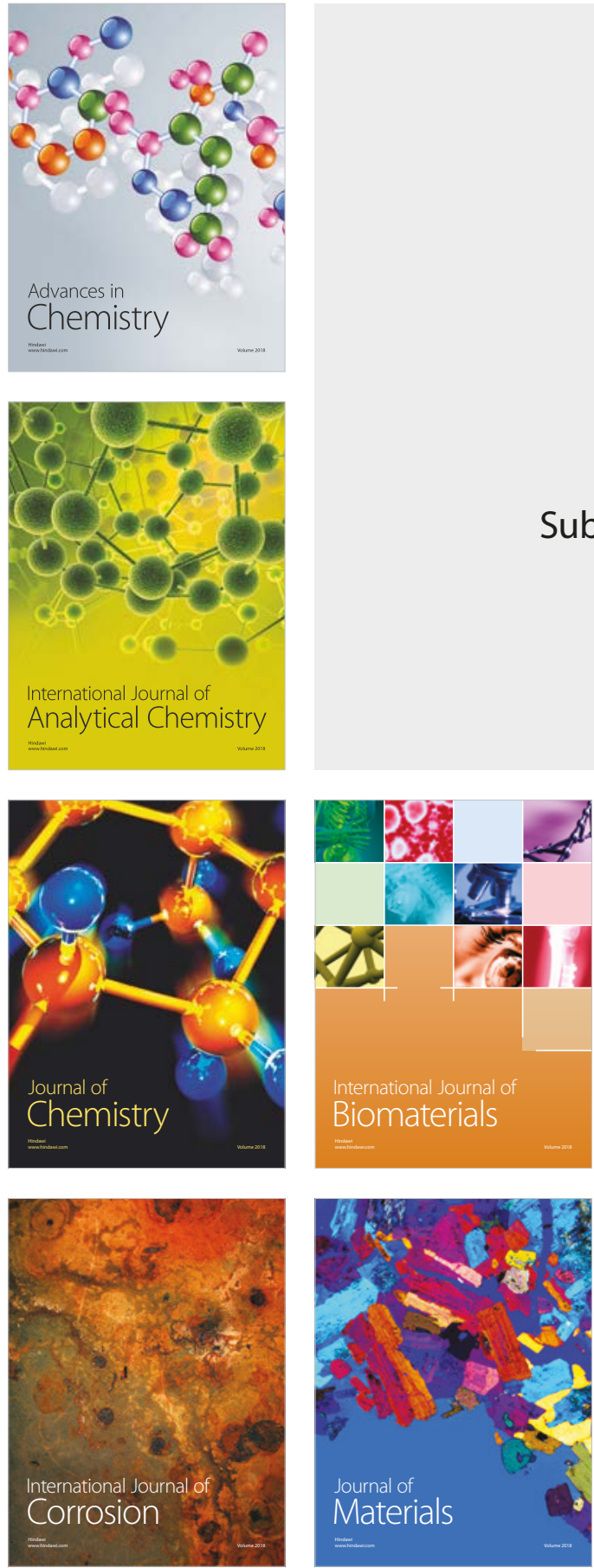

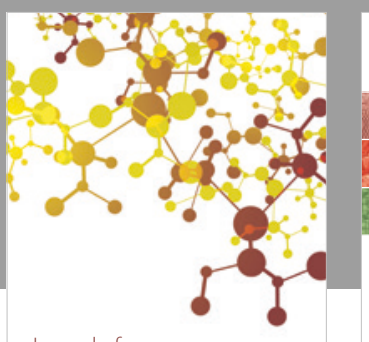

Journal of

Applied Chemistry
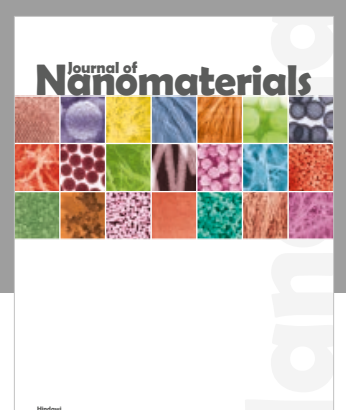

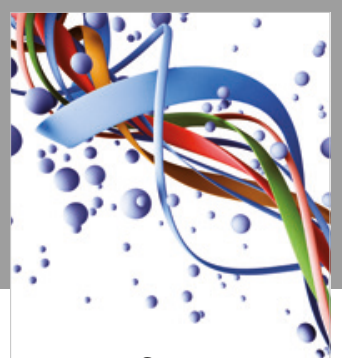

Scientifica

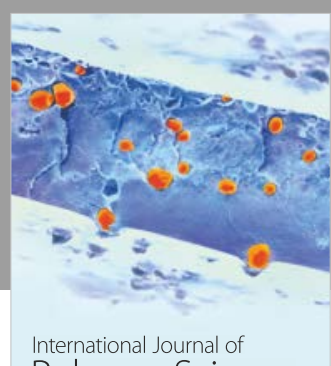

Polymer Science

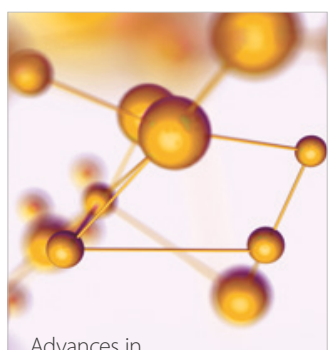

Physical Chemistry
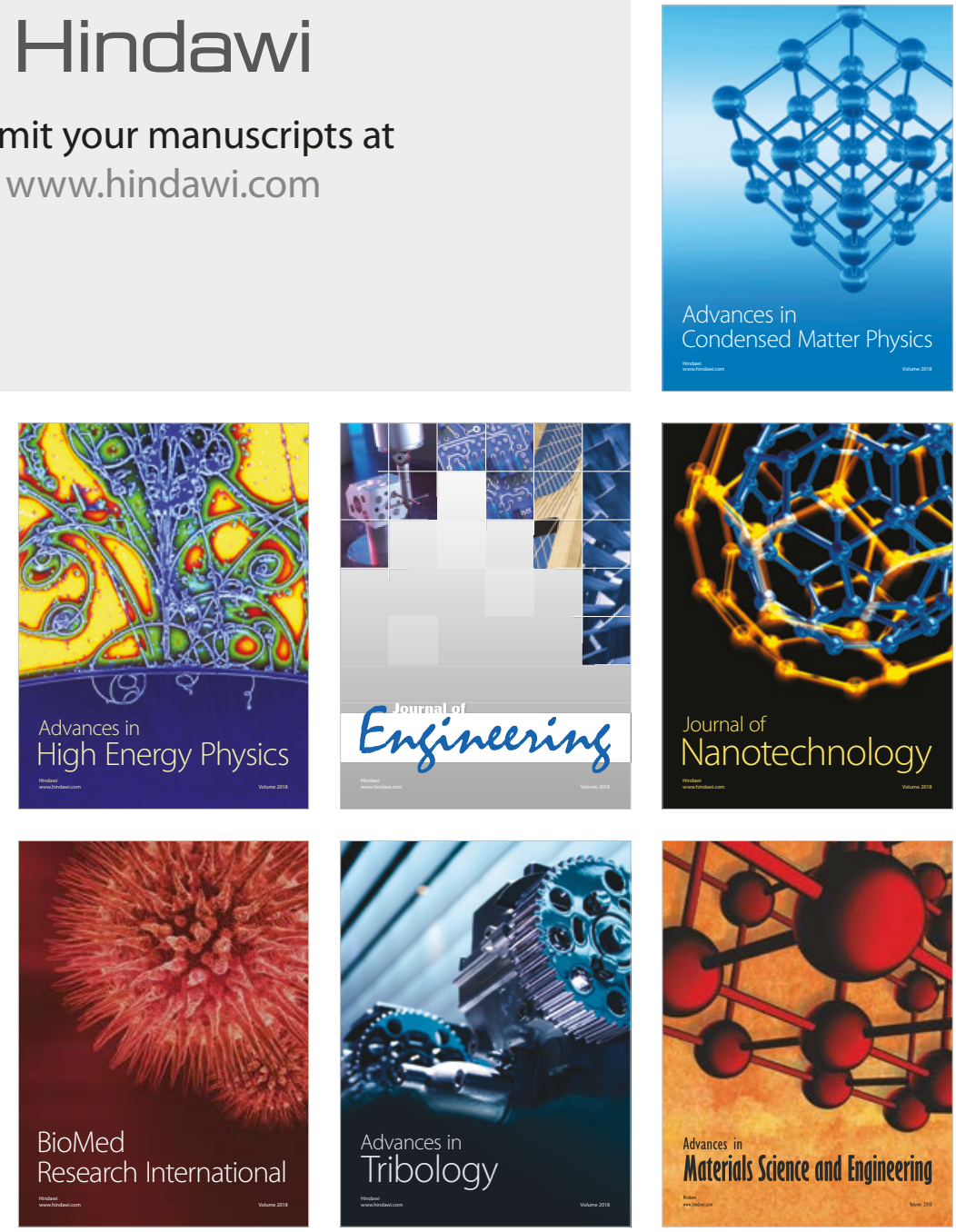